\title{
«Garbage reform» in Russia and the introduction of a new tax payment
}

\author{
Galina Semenova ${ }^{1,2, *}$ \\ 'Plekhanov Russian University of Economics, Stremyanny per., 36, Moscow, Russia \\ ${ }^{2}$ Moscow Region State University, Vera Voloshina St., 24, Mytishchi, Moscow Region, Russia
}

\begin{abstract}
Why does Russia need "garbage reform"? This reform was a consequence of the adopted strategy for environmental safety of Russia until 2025. This document recognized the existing problem with garbage and outlined ways to solve this problem. At the moment, about 30 billion tons of waste have accumulated at Russian landfills. More and more landfills are overcrowded, and garbage is almost not involved in secondary circulation and is not recycled. The construction of new landfills means, among other things, the use of land not for farming, but for creating dumps. This cannot go on indefinitely. The environmental safety strategy assumes that with the help of the "garbage reform", it is possible to solve such tasks as increasing environmental safety, recycling more waste for secondary use, reducing the burden on the environment, creating a unified system of collection, transportation, processing and disposal of waste in the country, and gradually move to a ban on the disposal of waste that has not been sorted, as well as to mechanical and chemical treatment. The subject of study is the reform of waste disposal. The purpose of the study is to identify the negative impact of garbage waste on the environment. Methodology. To study the topic, objects of waste disposal and the share of their processing were examined. Results - it is planned to completely change the waste collection and disposal system in Russia.
\end{abstract}

\section{Introduction}

Waste reform in Russia can be called a necessity, and not only because there is more and more waste - changes are required in terms of the organization of the entire system, in the approach to working with dumps and landfills. During the Soviet era, a single harmonious algorithm for the collection and disposal of waste worked in the country. However, in the modern world, the composition of waste has changed a lot, and disposal methods are outdated. In Soviet times, pre-sorting already existed; schoolchildren were engaged in it during the collection of waste paper and recyclable materials.

In the $90 \mathrm{~s}$, this system was abandoned. For example, plastic appeared, resulting in a large-scale garbage problem. Spontaneous damps began to form everywhere in all regions, landfills for the disposal of municipal solid waste (MSW) were overflowing, residents of

\footnotetext{
* Corresponding author: angela-1309.m@yandex.ru
} 
nearby settlements were suffocating from the stench. Seventy million tons of garbage was generated in Russia annually, and there was nowhere to recycle it.

The following terms appear in the norms of the current legislation:

MSW (municipal solid waste) is all kinds of waste that is generated in the course of human life (for example, during cooking, cleaning, repairing, throwing away old unnecessary pieces of furniture, clothing, etc.);

HSW (household solid waste) is a group of emissions from residential premises, which include things that have become unusable. In fact, these types of waste have many similarities. Garbage generated in the course of satisfying household needs should also be taken into account. In accordance with the new legal norms, citizens pay a fee for the removal of HSW. This waste is not related to construction waste. In this regard, citizens undertake to carry out its removal on an independent basis.

On January 1, 2019, the "garbage" reform began in Russia. In accordance with it, the fee for garbage collection is mandatory, a new utility tax payment has appeared - a separate fee for garbage collection. The payment is determined for each family member. The fees vary by region. In some regions it is small, in others it is up to 50 times higher. Tariff setting is carried out by the owners or management organizations.

Russian citizens paid for the removal of MSW before, but such a payment was included in the general line "Maintenance of housing", and the amount they paid was impossible to determine. Management companies or HOAs calculated the payment for garbage collection based on the area of the apartment, dividing the average monthly expenses for the removal of solid waste by the total area of the housing stock. From 2020, the payment becomes personal for each citizen, the regions are actively working on the amount in the new payment order [1].

Many regions have already calculated this amount. In some cases, the start of the "garbage reform" has been postponed - the State Duma adopted a special law for those regions that do not have time to organize garbage collection in a new way, through a special operator.

In those regions that have determined the amount of the new payment, it is usually between 100 and 150 rubles per person. That is, a family of three will pay a payment of about 400 rubles a month for the removal of MSW within the framework of the "garbage reform".

If earlier many organizations were involved in the removal of HSW, today only one company belongs to them - a regional operator. Regional waste management operators in each region are now selected through competitive procedures. In total, there can be one operator in each region. The winning company carries out activities for the collection, transportation, processing, recycling, neutralization, and disposal of waste of I - IV hazard classes.

The main task of the regional operator is to solve the problem with the removal and processing of waste in this region. The regional operator is responsible for all activities in this area, including - collects payments from the population, prepares and creates infrastructure for working with MSW, including the construction of complexes for processing, recycling, neutralization, and disposal of waste.

Also, its functions include the elimination of spontaneous dumps, garbage removal from the territories of apartment buildings, private sector, enterprises, and the construction of container sites. The regional operator has the right to conclude contracts with garbage companies. Using the GLONASS technology, it controls garbage trucks. Settlement with transport companies is based on the volume of garbage that is delivered to the place of sorting and processing. 


\section{Materials and Methods}

In 2019, the Russian economy generated 7.3 billion tons of waste. Almost all of this is industrial waste, which is not garbage in the usual sense. For example, statisticians consider the rock, which is taken out during the extraction of ore, and then piled into dumps as waste. Enterprises that are engaged in the extraction of minerals produce the bulk of waste 6.9 billion tons. Three quarters of this figure is in the coal industry.

Garbage in the usual sense that utilities take to landfills or special processing plants is called household solid waste (HSW) and municipal solid waste (MSW). The amount of household waste is also growing: in twenty years, the production of HSW has doubled. This is caused by the active use of packaging materials: polyethylene, plastic, paper, but it is not known exactly what proportion of the total volume of waste is packaging [5].

At the end of 2018 , only $4-5 \%$ of the waste was burned. The 2019 garbage reform initiators plan to recycle up to $60 \%$ in 2024 and $95 \%$ in 2030 . For this, 130 recycling complexes should be built to eliminate all unauthorized landfills and develop an efficient recycling structure.

In Russia, the waste-processing industry is almost absent [2]. This factor is a very negative aspect, because cities and towns are heavily littered. In Russia, there are 1,000 officially registered landfills and 15,000 official dumps, 17,000 places for waste disposal are unauthorized (Fig. 1).

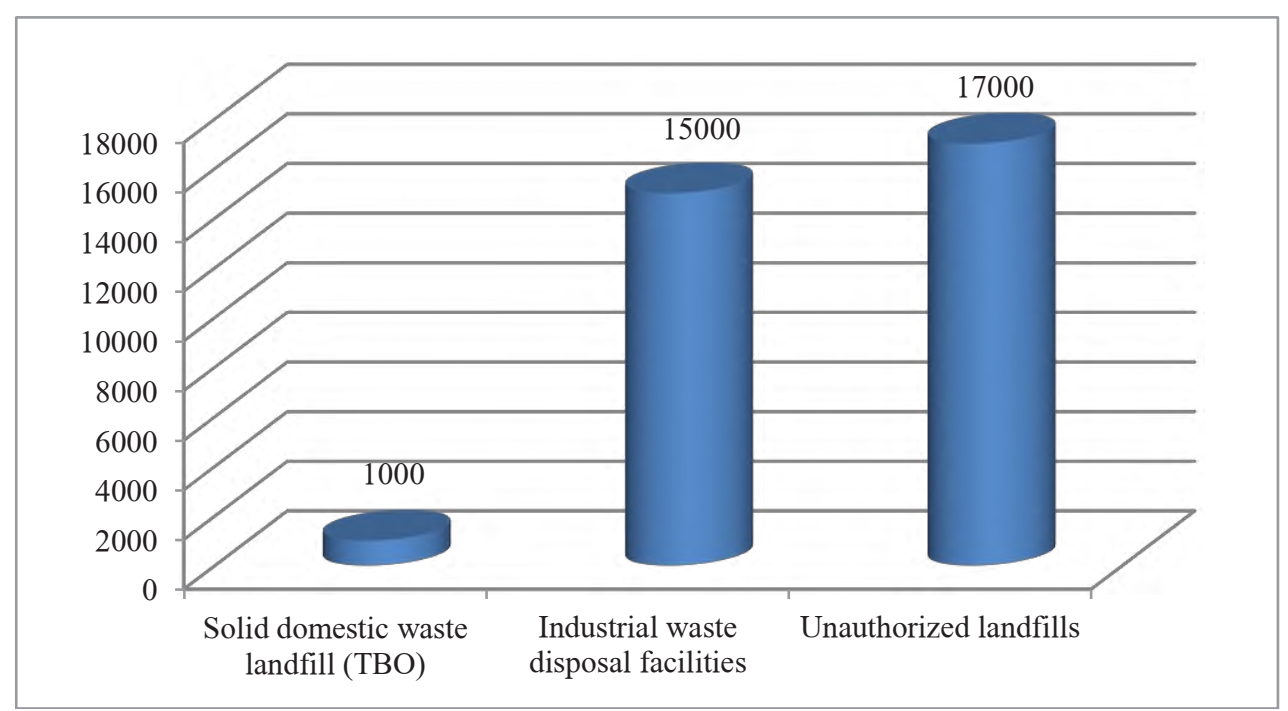

Fig. 1. Waste disposal facilities in Russia, in units.

According to Federal Service for Supervision of Natural Resource Usage, landfills in Russia occupy 5 million hectares. It is about the size of the Netherlands. The area occupied by waste increases by 500 thousand hectares every year. At this rate, landfills will occupy $1.5 \%$ of the entire area of Russia by 2060 [6]. Landfill areas in Russia and other countries are shown in Fig. 2. 


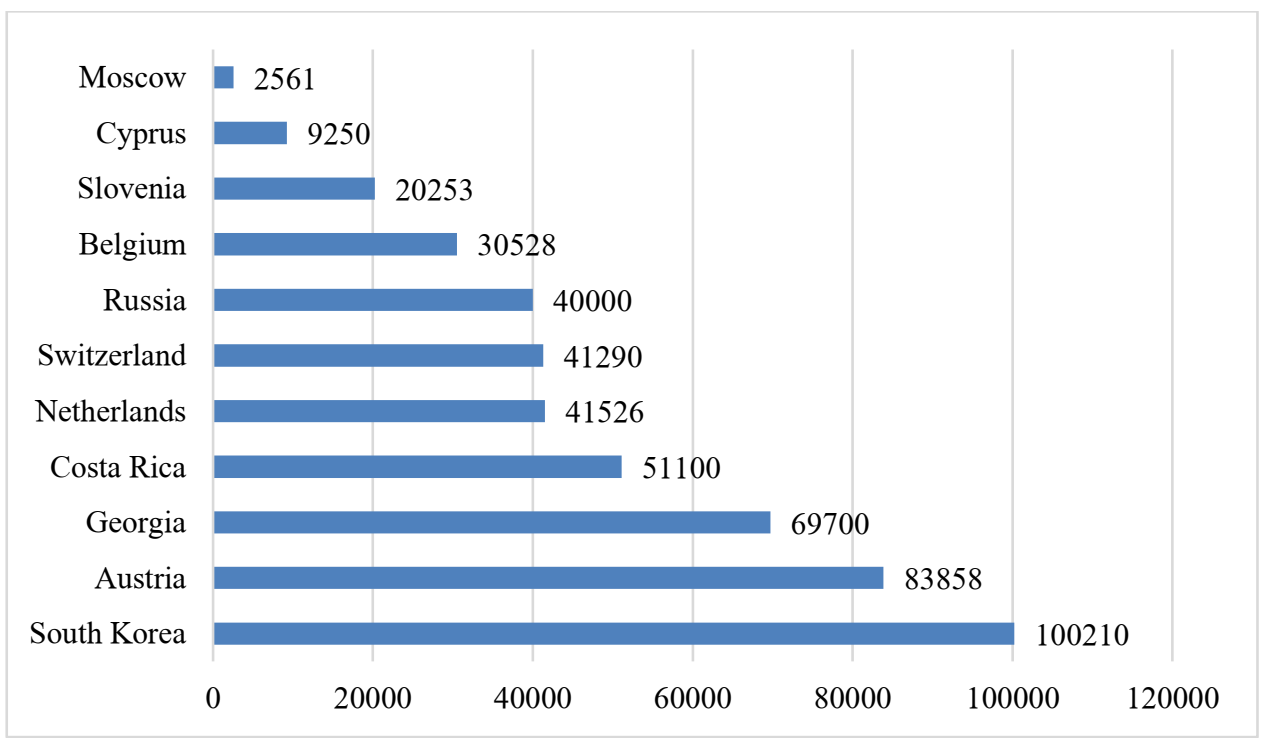

Fig. 2. Landfill areas in Russia and other countries (Source: World Bank. Created with Datawrapper), $\mathrm{km}^{2}$.

For example, the dynamics of landfill growth is surprising - the figure increases every year by the size of the territory of Moscow within its new borders. Moscow authorities are taking measures to get rid of industrial and household waste. Every year, 8-10 million tons of garbage are sent to the territory of the Moscow region. Every inhabitant of the capital accounts for 600 kilograms of household waste. There are 39 official landfills for household waste in the Moscow Region, 24 facilities no longer accept garbage due to the termination of the license. Damps that continue to function also have difficulty accepting the entire volume [3].

We deal with garbage every day. A bin of rubbish is thrown into garbage containers every day. If the collection system is well established, no one in the city pays attention to the amount of garbage that is produced and thrown away by only one house in one day.

More than a third of the volume of the trash bin of Russian people is food waste, $17 \%$ glass and iron products, about $20 \%$ - paper and cardboard, which could serve as secondary raw materials if thrown into bins for separate waste collection, $10 \%$ - plastic products, it is also a potential recyclable material.

In different countries, these proportions vary greatly: in China and Brazil, mainly food waste is sent to the trash, in the USA - paper, and in the UK - plastic.

What amount of garbage a typical Russian person produces per year in comparison with residents of other countries (Fig. 3)? 


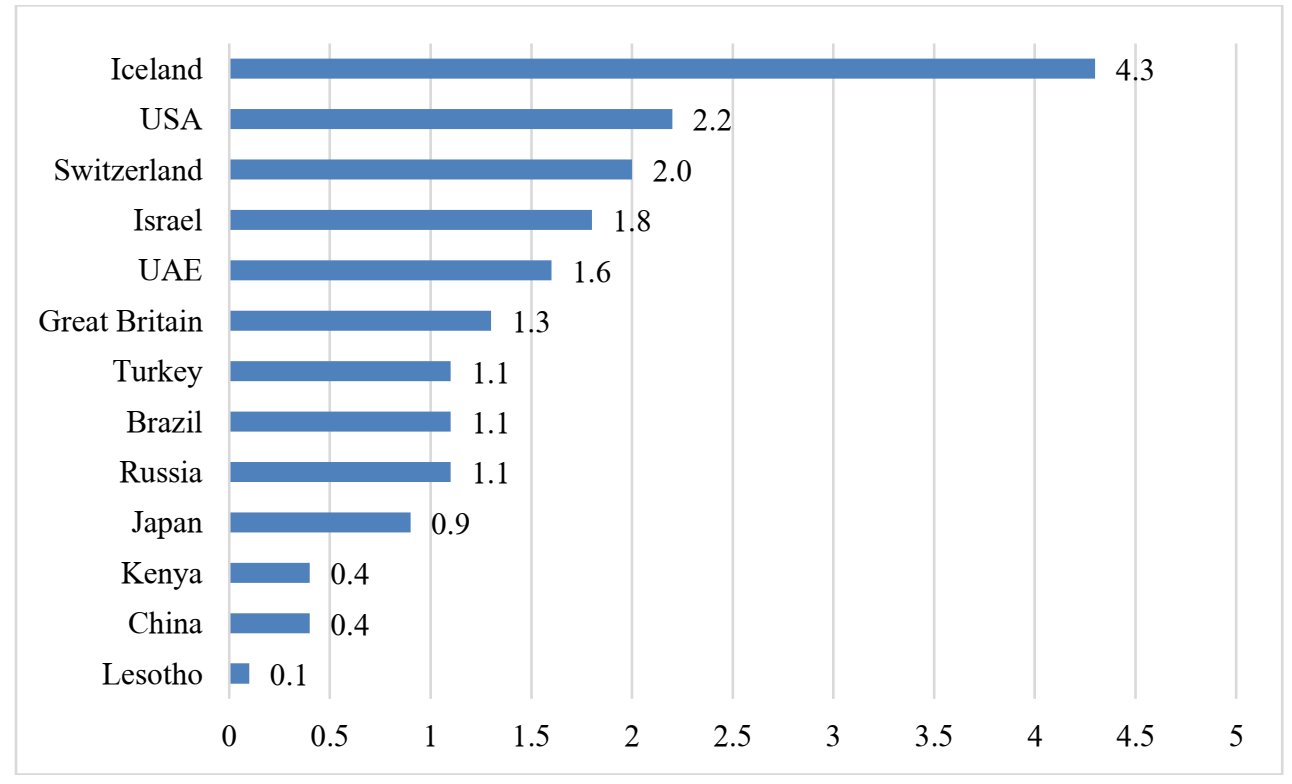

Fig. 3. The amount of waste produced by one person, kg/day. Source: World Bank. Created with Datawrapper.

The average Russian person produces about two cubic meters of garbage a year - about $400 \mathrm{~kg}$ - this is about $1.1 \mathrm{~kg}$ per day. According to the statistics of the World Bank, Russia does not look so bad against the global background: this figure is $1 \mathrm{~kg}$ in the whole planet. Most of the garbage is generated by the citizens of Iceland - $4.3 \mathrm{~kg}$ per day, the least - the citizens of Lesotho, only $100 \mathrm{~g}$.

If we give approximate calculations for the disposal of household waste in one day, more than $30 \%$ of which are recyclable materials in the form of plastic and paper, then they will amount to: 10 liters of garbage ( 0.02 cubic meters) are thrown out of one apartment every day $*$ for 160 apartments $=1600$ liters or 3 cubic meters of household waste daily for two five-story buildings.

And there are many such houses, for example, in Moscow, and not all of them are fivestory buildings. With approximate statistics according to various estimates, up to 7.5 million tons of MSW are generated annually in Moscow alone.

Most of the domestic waste in Russia is taken to dumps. There are now about 15,000 official dumps in the country. But no one counts how much waste Russians throw away in the nearest forest plantation [4].

According to the Ministry of Natural Resources, only $8 \%$ of waste is recycled. For example, 9 million tons of waste paper, 2 million tons of plastic and 0.5 million tons of glass are sent to dumps every year - all this could be recycled, but there is simply no system for collecting such waste or special factories in the country.

Another problem is food waste, which accounts for more than a quarter of all HSW. According to the Association of Retail Companies, 5\% of this waste - 700 thousand tons per year - is expired products from stores. Products that are approaching the end of their shelf life could be distributed to those in need, but it is more profitable to destroy them. The taxes that retailers have to pay when donating goods to charity can be up to $40 \%$ of their value. And it is illegal to give overdue to charity, so it is cheaper to dispose of products. The cost of taking a ton of garbage to the landfill in Moscow is only 600-800 rubles.

Waste processing in Russia is shown in Fig. 4. Basically, the share of recyclable waste is $30 \%$ paper and cardboard, $20 \%$ polyethylene. 


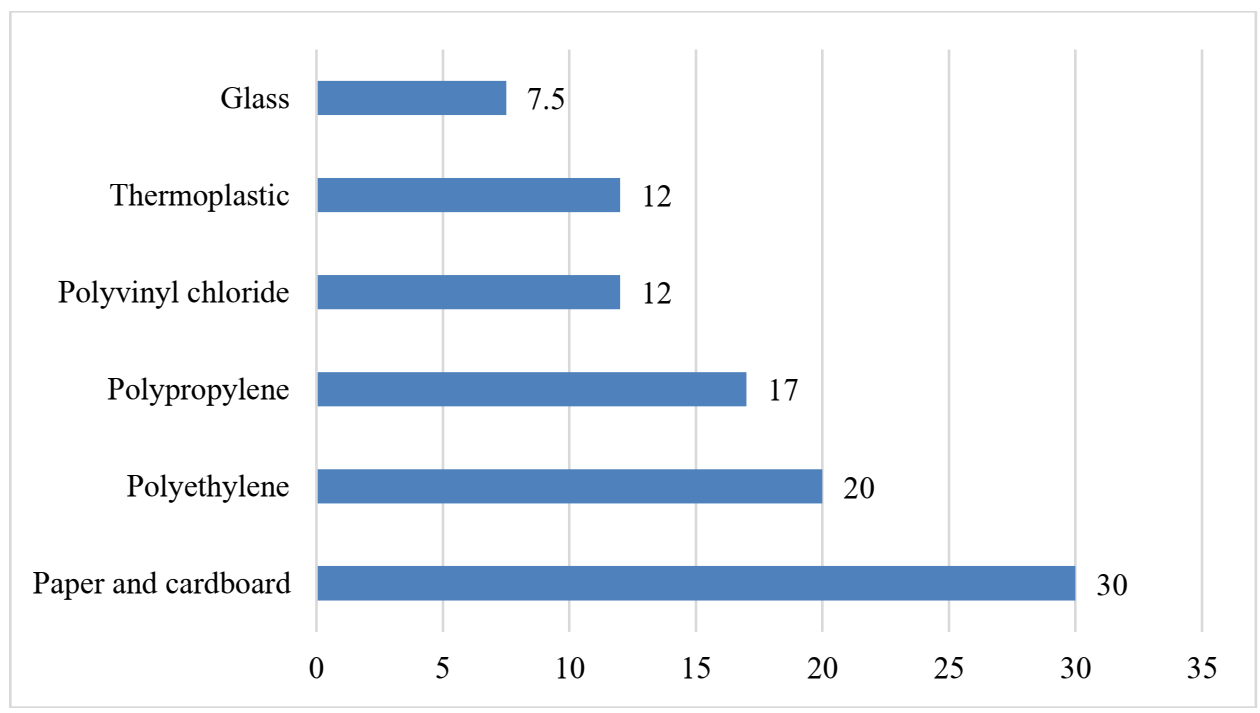

Fig. 4. Share of recycled waste in Russia (Source: World Bank. Created with Datawrapper), \%.

Russians consider landfills the second most important environmental problem after air pollution. $85 \%$ of Russians are ready to give up plastic bags in supermarkets. Manufacturers of reusable shopping bags believe that this market will grow by about $20 \%$ over the next three years, primarily because Russians are willing to ditch plastic bags to preserve the environment. Today, the majority of Russians carry purchases from shops in plastic bags - $68 \%$ and only $18 \%$ use their bags and backpacks (Fig. 5).

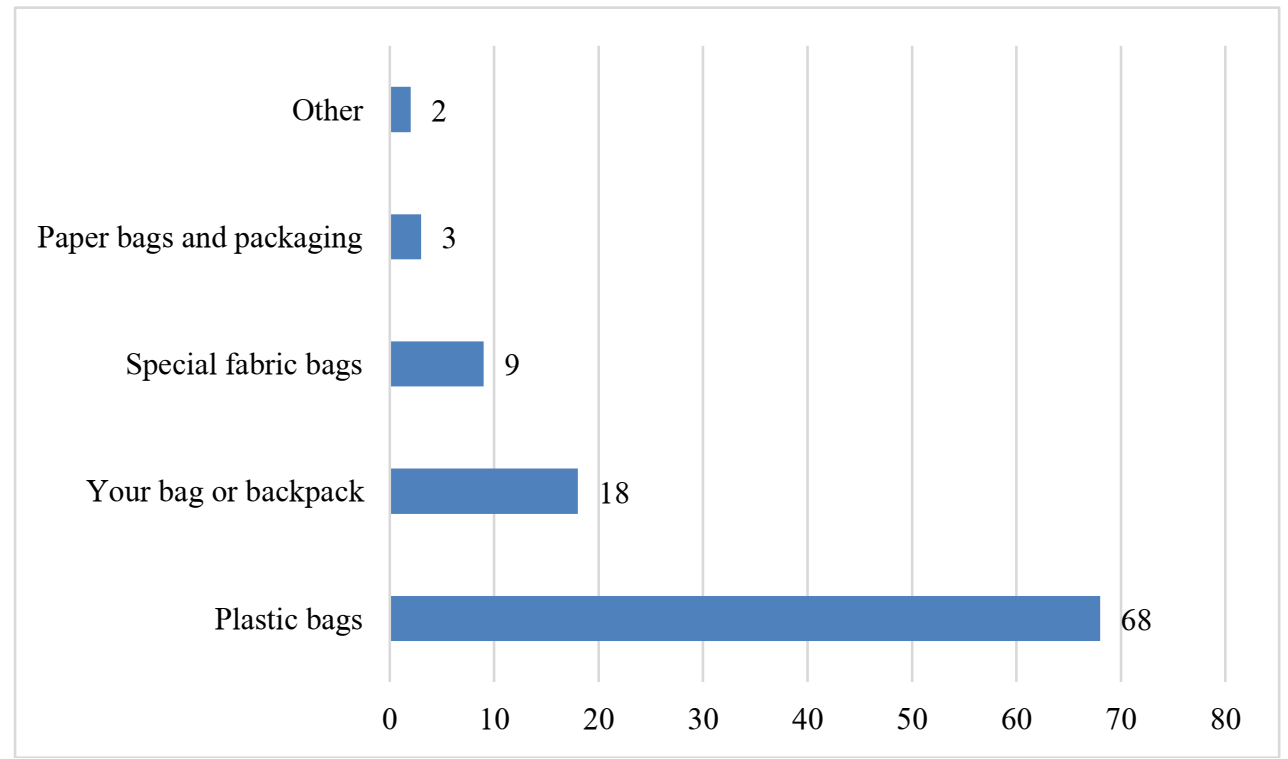

Fig. 5. Means used by the population for carrying goods from stores (Source: World Bank. Created with Datawrapper), \%.

Domestic waste heaps and environmental pollution have become a national problem in the country. The increase in the amount of plastic occurs exponentially. Garbage dumps threaten to develop into an ecological disaster [5]. 
Today, unauthorized damps remain illegal. The mass pollution is growing every year. It is proposed to punish organizations in the amount of 800,000 rubles, and citizens $-8,000$ rubles. Officials guilty of throwing garbage in the wrong place will receive a fine of 70,000 rubles. It was proposed to suspend the activities of legal entities for up to 3 months.

In addition to the fine, the culprit will be obliged to liquidate the damp and restore and improve the soil. This will incur additional costs. If illegal waste disposal is detected, citizens have the right to file a complaint with the local administration or the environmental prosecutor's office.

The implementation of the garbage reform requires 78 billion rubles. $30 \%$ will be financed by the state in the form of subsidies for leasing and concessions. This means that the complexes should be built by regional operators with the support of the state, the rest of the costs should be compensated by payments from the population.

\section{Results}

The garbage reform presupposes the separate collection of waste raw materials, which will now be handled not by municipal services, but by special regional operators. It is planned that the funds received from the increase in tariffs will be used for the construction of recycling plants and the closure of old landfills.

Features of the innovation for garbage disposal:

- responsibility for the formation of landfills, the development of waste disposal schemes and the selection of the operating company is in the hands of local authorities;

- calculation of fees for the transportation of waste now depends on the standards for the accumulation of solid and bulky waste per person, rather than per square meters;

- setting tariffs for garbage disposal is carried out by the state committee, and standards - by local authorities (the latest news of the garbage reform shows that so far only 35 constituent entities of the Russian Federation have formed prices for the service);

- participation in programs for the distribution of waste into "wet" and "dry" presupposes payment benefits (up to a maximum of 50\%);

- earlier, the payment for garbage collection in the payment documents of Russians was included in the line "Maintenance", but today it is written separately.

Under the new rules, payment is charged for each person registered in the apartment or house. If no one is registered in the apartment, then the calculation is based on the number of owners.

In each region, tariffs are approved by local authorities. In some regions, the tariff is calculated using a complex formula.

The formula for calculating the total tariff is as follows:

$$
\text { Tto }=\text { Tmax } * \mathrm{~N} / 12
$$

where Tto - total tariff,

Tmax - maximum tariff for $1 \mathrm{~m}^{3}$ of waste,

$\mathrm{N}$ - rate for the removal of solid and bulky waste per person. The rate is determined by summing up the annual rates of waste production per person and dividing by the area rate per person.

For example, a person annually creates $1.56 \mathrm{~m}^{3}$ and $0.49 \mathrm{~m}^{3}$ of various types of waste. The indicators are summed up and divided by the norm of square meters per 1 tenant -18 $\mathrm{m}^{2}$.

As a result, the annual rate $(\mathrm{N})$ will be:

$$
\mathrm{N}=\left(1.56 \mathrm{~m}^{3}+0.49 \mathrm{~m}^{3}\right) / 18=0.1139
$$


It should be noted that the population is required to regularly pay for the service provided and dispose of waste in strictly designated places. There is an opportunity to minimize the fee if it is proved that fewer people live in the apartment or house than it is prescribed (for example, a person signed a contract for military service, went abroad or received a long business trip, is studying in another region, etc.).

In February 2019, many citizens of the Russian Federation saw in their bills for utilities a separate line "For the provision of services for the management of MSW". On average, you will have to pay 90-130 rubles for each registered resident. According to Vladimir Burmatov, head of the State Duma committee on work with public associations, the following increase in waste collection fees is observed:

- Nizhny Novgorod region - almost 17 times;

- Ingushetia - 18 times;

- Astrakhan region - 10 times;

- Voronezh region - 5 times;

- $\quad$ Perm Territory - 7 times.

The projected growth rate of payments for the service for the removal of household waste will be $12 \%$. On average, taking into account the "garbage" reform, tariffs across the country will be added monthly by 30 rubles. Indexation is planned to be carried out every month - first by $1.7 \%$, and from mid-2019 - by $2.4 \%$.

\section{Conclusions}

Russia sees the garbage problem and is trying to fight it. Back in 2013, the Ministry of Natural Resources adopted a large document - a strategy for the management of municipal solid waste. Garbage reform in Russia is designed until 2030. It is assumed that by this time, it will be possible to completely change the garbage collection and disposal system. But this requires:

1. Teach children to separate garbage, not throw it anywhere and generally produce less waste.

2. There should be no illegal dumps in the country, and gardens should bloom in these places. Impose large fines for those who throw garbage where it is not supposed to.

3. All waste is separated. In each apartment, there are two trash bins under the sink: in one you need to throw out what can be recycled - glass, paper, plastic, in the other - everything else.

4. All rubbish that can be used again is recycled. For this, factories are operating throughout the country that extract valuable components from waste. Compost is produced and methane is extracted from food waste, fuel briquettes are made from wood and sawdust.

5. Those who throw recyclable waste into dumps are punished.

6. Wastes that cannot be recycled are neutralized at high temperatures. Landfills no longer stink a mile away, you can live next to them.

7. There is only one company in each region, which is responsible for the entire waste management cycle - from removing containers from yards to recycling. Such a company - it is called a regional operator - is selected by competition every ten years.

8. Tariffs for waste collection and disposal are calculated according to formulas that are understandable for everyone. There is a single tariff in each region throughout its territory. 


\section{References}

1. D.A. Barabanshchikov, A.F. Serdyukova, Young scientist 25, 101-104 (2017) https://moluch.ru/archive/159/44714/

2. T.V. Gaponova, SCI-ARTICLE 1 (2014)

3. G. Semenova, E3S Web of Conferences 138, 02012 (2019) https://doi.org/10.1051/e3sconf/201913802012

4. G. Semenova, E3S Web of Conferences 91, 08046 (2019) https://doi.org/10.1051/e3sconf/20199108046

5. A.D. Sukhoruchenko, SCI-ARTICLE 1 (2014)

6. Recycling Basics. United States Environmental Protection Agency, https://www.epa.gov/recycle/recycling-basics 